\title{
Abdomen CT findings in a COVID-19 patient with intestinal symptoms and possibly false negative RT-PCR before initial discharge
}

\author{
Yi Guo ${ }^{1 \#}$, Xiaofei Hü ${ }^{2 \#}$, Fei Yu ${ }^{1}$, Jiao Chen ${ }^{1}$, Wei Zheng ${ }^{1}$, Jun Liu ${ }^{1}$, Ping Zeng ${ }^{1}$ \\ ${ }^{1}$ Department of Radiology, Chongqing University Central Hospital, Chongqing 400014, China; ${ }^{2}$ Department of Radiology, Southwest Hospital, \\ Third Military Medical University (Army Medical University), Chongqing 400038, China \\ \#These authors contributed equally to this work.
}

Correspondence to: Jun Liu; Ping Zeng. Department of Radiology, Chongqing University Central Hospital, Chongqing 400014, China.

Email: JunLiu_cquch@163.com; pingzeng_cquch@163.com.

Submitted Mar 19, 2020. Accepted for publication Apr 22, 2020.

doi: 10.21037 /qims-20-463

View this article at: http://dx.doi.org/10.21037/qims-20-463

\section{Introduction}

In December 2019, an outbreak of COVID-19 pneumonia started in Wuhan, Hubei province, China; and spread rapidly across China and to more than 200 countries and regions overseas; and has become a global health concern. On March 11th, 2020, COVID-19 was declared to be a pandemic by the World Health Organization. Fever and cough are the main symptoms of an infected person. Other symptoms include dyspnea, sore throat, myalgia, fatigue, headache, diarrhea (1). In this report, we describe the abdomen CT features of a case of COVID-19 demonstrating intestinal symptoms.

\section{Case description}

A 29-year-old man presented to the hospital on January 30th, 2020, with a 2-day history of fever and diarrhea (yellow watery stools 5 times per day). At admission, his body temperature was $37.3^{\circ} \mathrm{C}\left(99.1^{\circ} \mathrm{F}\right)$. Unenhanced chest CT showed multiple consolidative peripheral opacities with ground-glass opacities in bilateral lungs (Figure 1A). Realtime pluorescence polymerase chain reaction (RT-PCR) of his nasopharyngeal swab and anal swab samples were positive for the SARS-CoV-2 nucleic acid testing (NAT). He did not have contact history with confirmed COVID-19 patients, and thus belonged to community-acquired case with unknown infection source.

After 14 days of treatment with a combination of lopinavir/ritonavir, ribavirin and human interferon inhalation, the patient's diarrhea and fever symptoms relieved and RT-PCR of the patient's nasopharyngeal swab, anal swab, and sputum samples were all negative for two times, which met the discharge standard (2). Therefore, the patient was transferred to the isolation ward for observational quarantine.

However, 2 days later the patient suffered symptom recurrence including diarrhea (yellow watery stool three times per day) and hyperthermia $\left(37.7{ }^{\circ} \mathrm{C}, 99.9^{\circ} \mathrm{F}\right)$. Laboratory studies showed elevated levels for C-reactive protein $(1.7 \mathrm{mg} / \mathrm{L}$; normal range, $0-3.0 \mathrm{mg} / \mathrm{L})$ and lymphopenia (lymphocyte count: $0.99 \mathrm{~g} / \mathrm{L}$; normal range, 1.10-3.20 g/L). Unenhanced chest and abdominal CT scans were obtained on February $16^{\text {th }}, 2020$ (Figure $1 B, C, D, E, F, G, H)$. Chest CT scan showed the density of some patchy solid shadows was reduced, showing a ground glass density similar to "melting sugar" (Figure 1B). Axial images of abdominal CT scan showed segmental wall swelling, involving a segment of the jejunum in the left upper quadrant, with thickened mesenteric vessels and mild lymph nodes enlargement (Figure 1C,D,E,F). Coronal images of abdominal CT scan displayed segmental wall swelling of the jejunum, with mesenteric vessels dilatation (Figure 1G,H). RT-PCR of nasopharyngeal swab and anal 

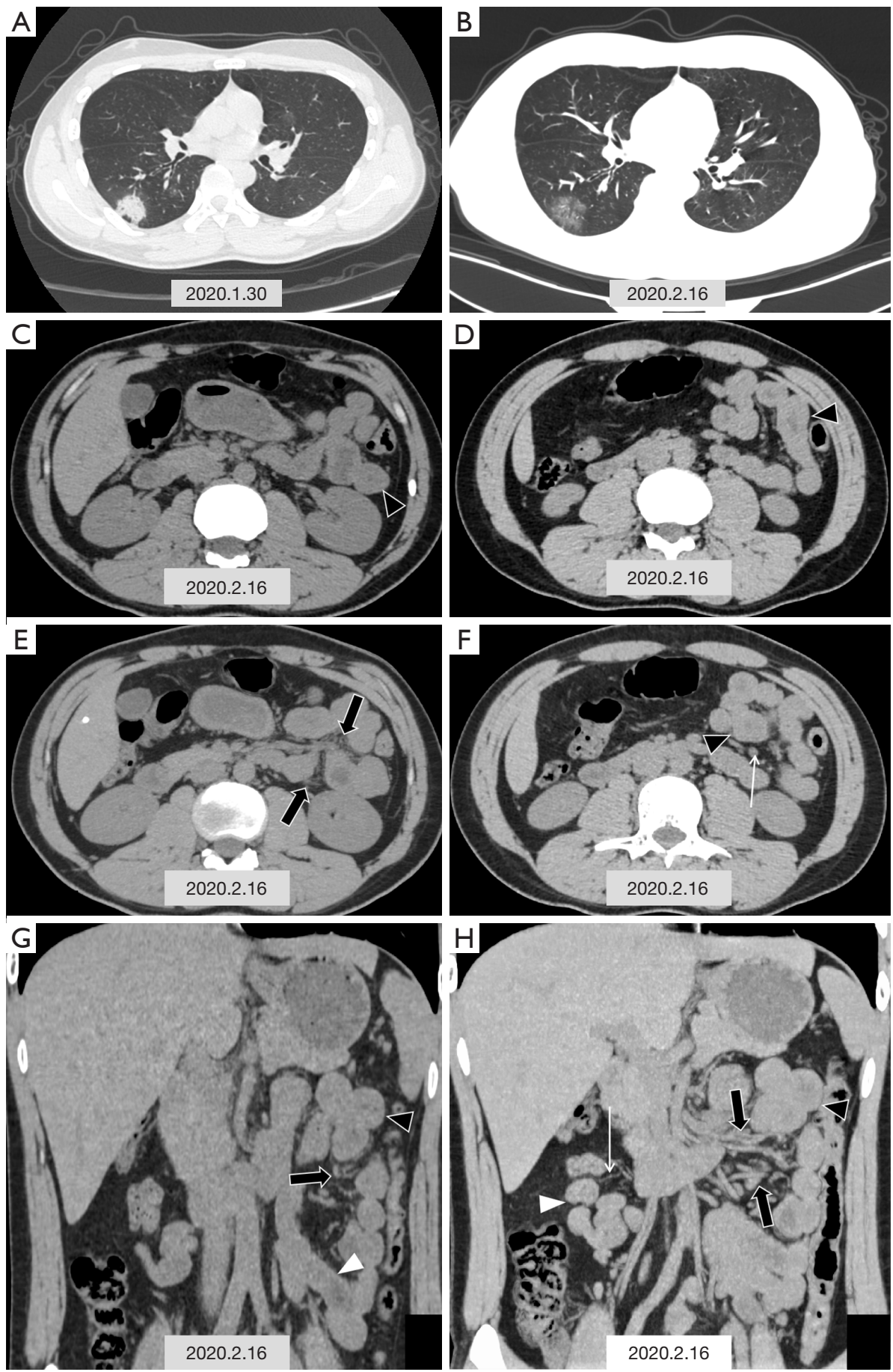

Figure 1 CT images in a 29-year-old man with fever and diarrhea, and RT-PCR of nasopharyngeal swab and anal swab samples tested positive for SARS-CoV-2. (A) Chest CT scan obtained on the first admission on January 30th, 2020 shows one typical consolidative lesion among multiple opacities in subpleural region of the right lower lobe (black triangle); (B,C,D,E,F,G,H) chest and abdominal CT scans obtained on February 16th, 2020; (B) show the density of some patchy solid shadows reduced, demonstrating a ground glass density similar to "melting sugar" (black triangle); (C,D,E,F) axial images of abdominal CT scan show segmental wall swelling (black triangle) involving a segment of the jejunum in the left upper quadrant, with thickened mesenteric vessels (black arrow) and mild lymph nodes enlargement (white arrow); (G,H) coronal images of abdominal CT scan display segmental wall swelling of the jejunum (black triangle), with mesenteric vessels dilatation (black arrow). white triangle: normal intestinal wall, white arrow: mesenteric vessels. 
swab samples tested negative initially; however, the same test came out positive for SARS-CoV-2 on re-examination the next day.

This patient had no previous medical history for inflammatory bowel diseases. And RT-PCR showed that his nasopharyngeal swab and anal swab were both positive for SARS-CoV-2. Therefore, the patient was eventually diagnosed with intestinal SARS-CoV-2 infection (3).

\section{Discussion}

The main abdominal CT features in this case included the following three aspects: segmental wall swelled involving of the jejunum in the left upper quadrant; mesenteric vascular enlargement; and lack of inflammatory exudative changes around the swollen intestine. The primary CT feature, segmental wall swelling, was consistent with the pathological features of segmental wall thickening changes of the intestinal wall reported by COVID-19 at autopsy (4). The main abdominal CT features were nonspecific, which were similar to some other inflammatory bowel diseases such as Crohn's disease and ulcerative colitis (5). However, it is not clear whether the sign with no inflammatory exudative changes around the intestinal tract was related to the different disease progression stage. According to the guideline for the diagnosis and treatment of novel coronavirus (COVID-19) infected pneumonia (trial seven edition) (2), the SARS-CoV-2 infected the intestine predominantly involving the intestinal mucosa, leading to denaturation, necrosis and exfoliation. It was speculated that the infection progressed outwards from the intestinal mucosal layer, and that exudation around the intestinal tract is not evident in mild type of COVID-19.

SARS-CoV-2 binds to their target cells through angiotensin-converting enzyme 2 (ACE2), which is expressed by epithelial cells of the lung, intestine and blood vessels. Hence, intestinal epithelial cells may also be infected the same as alveolar epithelial cells $(6,7)$. Similar to other beta human coronavirus $(\mathrm{HCoV})$, even with no respiratory symptom, COVID-19 patients also showed signs of digestive tract involvement, such as diarrhea, nausea, and vomiting. It has been found that $19.4 \%$ experienced diarrhea as the initial symptom in their illness course (8). Moreover, SARS-CoV-2 could be detected in stool samples of COVID-19 patients $(9,10)$. At present, the diagnosis and treatment of COVID-19 is mainly focused on pulmonary infection, while other organs are easily neglected. In this case, positive findings were found in the abdominal CT on February 16th, 2020. However, it may be possible that positive results could be found if abdominal CT was performed on January 30th, 2020 when the patient suffered diarrhea. Thus, the abdominal CT could be used to assess the intestine condition and provide objective evidence for patients with suspected gastrointestinal involvement, especially for those with positive RT-PCR results of stool samples or anal swab.

In conclusion, the abdominal CT features of COVID-19 are described in this case. For those patients with intestinal symptoms, positive results for RT-PCR of stool samples or anal swab and above-mentioned abdominal CT features may suggest intestinal SARS-CoV-2 infection.

\section{Acknowledgments}

Funding: This work was supported by the National key research and development Project (2018YFC0114404).

\section{Footnote}

Conflicts of Interest: All authors have completed the ICMJE uniform disclosure form (available at http://dx.doi. org/10.21037/qims-20-463). The authors have no conflicts of interest to declare.

Ethical Statement: Patient and CT images Our institutional review board waived written informed consent for this retrospective case series that evaluated de-identified data and involved no potential risk to patients [No: 2020(9) of ethics board].

Open Access Statement: This is an Open Access article distributed in accordance with the Creative Commons Attribution-NonCommercial-NoDerivs 4.0 International License (CC BY-NC-ND 4.0), which permits the noncommercial replication and distribution of the article with the strict proviso that no changes or edits are made and the original work is properly cited (including links to both the formal publication through the relevant DOI and the license). See: https://creativecommons.org/licenses/by-nc-nd/4.0/.

\section{References}

1. Wang D, Hu B, Hu C, Zhu F, Liu X, Zhang J, Wang B, Xiang H, Cheng Z, Xiong Y, Zhao Y, Li Y, Wang X, Peng Z. Clinical characteristics of 138 hospitalized patients with 2019 novel coronavirus-infected pneumonia in Wuhan, 
China. JAMA 2020. [Epub ahead of print]. doi: 10.1001/ jama.2020.1585.

2. General Office of National Health Committee. Office of State Administration of Traditional Chinese Medicine. Notice on the issuance of a programme for the diagnosis and treatment of novel coronavirus (COVID-19) infected pneumonia (trial seven edition). 2020. Available online: http://www.nhc.gov.cn/xcs/zhengcwj/202003/46c9294a7df e4cef80dc7f5912eb1989.shtml

3. Peiris JS, Chu CM, Cheng VC, Chan KS, Hung IF, Poon LL, Law KI, Tang BS, Hon TY, Chan CS, Chan KH, Ng JS, Zheng BJ, Ng WL, Lai RW, Guan Y, Yuen KY, HKU/UCH SARS Study Group. Clinical progression and viral load in a community outbreak of coronavirusassociated SARS pneumonia: a prospective study. Lancet 2003;361:1767-72.

4. Liu Q, Wang RS, Qu GQ, Wang YY, Liu P, Zhu YZ, Fei G, Ren L, Zhou YW, Liu L. Gross examination report of a COVID-19 death autopsy. Fa Yi Xue Za Zhi 2020;36:21-3.

5. Kedia S, Sharma R, Sreenivas V, Madhusudhan KS, Sharma V, Bopanna S, Pratap Mouli V, Dhingra R, Yadav DP, Makharia G, Ahuja V. Accuracy of computed tomographic features in differentiating intestinal tuberculosis from Crohn's disease: a systematic review with meta-analysis. Intest Res 2017;15:149-59.

6. Ding Y, He L, Zhang Q, Huang Z, Che X, Hou J, Wang H, Shen H, Qiu L, Li Z, Geng J, Cai J, Han H, Li X, Kang W, Weng D, Liang P, Jiang S. Organ distribution

Cite this article as: Guo Y, Hu X, Yu F, Chen J, Zheng W, Liu J, Zeng P. Abdomen CT findings in a COVID-19 patient with intestinal symptoms and possibly false negative RT-PCR before initial discharge. Quant Imaging Med Surg 2020;10(5):1158-1161. doi: 10.21037/qims-20-463 of severe acute respiratory syndrome (SARS) associated coronavirus (SARS-CoV) in SARS patients: implications for pathogenesis and virus transmission pathways. J Pathol 2004;203:622-30.

7. To KF, Lo AW. Exploring the pathogenesis of severe acute respiratory syndrome (SARS): the tissue distribution of the coronavirus (SARS-CoV) and its putative receptor, angiotensin-converting enzyme 2 (ACE2). J Pathol 2004;203:740-3.

8. Han C, Duan C, Zhang S, Spiegel B, Shi H, Wang W, Zhang L, Lin R, Liu J, Ding Z, Hou X. Digestive symptoms in COVID-19 patients with mild disease severity: clinical presentation, stool viral RNA testing, and outcomes. Am J Gastroenterol 2020. [Epub ahead of print]. doi: 10.14309/ ajg.0000000000000664.

9. Zumla A, Hui DS, Perlman S. Middle East respiratory syndrome. Lancet 2015;386:995-1007.

10. Guan WJ, Ni ZY, Hu Y, Liang WH, Ou CQ, He JX, Liu L, Shan H, Lei CL, Hui DSC, Du B, Li LJ, Zeng G, Yuen KY, Chen RC, Tang CL, Wang T, Chen PY, Xiang J, Li SY, Wang JL, Liang ZJ, Peng YX, Wei L, Liu Y, Hu YH, Peng P, Wang JM, Liu JY, Chen Z, Li G, Zheng ZJ, Qiu SQ, Luo J, Ye CJ, Zhu SY, Zhong NS, China Medical Treatment Expert Group for Covid-19. Clinical characteristics of coronavirus disease 2019 in China. N Engl J Med 2020. [Epub ahead of print]. doi: 10.1056/ NEJMoa2002032. 